\title{
Analysis of the Importance of Construction Management at Solar Power Station in the UK
}

Fu Tan

\author{
School of Engineering, University of Connecticut, Storrs, Connecticut 06269, United States \\ fu.tan@uconn.edu
}

\begin{abstract}
The construction management industry is a significant area that offers more economic development in the country. The organization's top managerial staff and designers are required to collaborate during the interaction. Also it is to work out the Net Present Value, internal Rate of Return and other expense spending issues of the whole venture for the development of Hot Salt Storage. It is important to note that personnel management is recognized with its pertinence in the association of a successful labor force.UK's sustainable power sources have increased from $15.9 \%$ expanded to $25.9 \%$. This research uses qualitative and qualitative (Mixed) methods to analyze the importance of construction management at solar power station in the UK. This article proves that in construction management, cost control and personnel control are indispensable elements to help the project progress smoothly and be better managed.
\end{abstract}

Keywords: Construction management, Development projects, benefits, personnel management, Interaction

\section{INTRODUCTION}

The use of solar energy in United Kingdom (UK), will help eradicate the dependence on oil which affects the country's development. Therefore, the development of solar power stations is the most essential step. Luckily, there are approximately 250 sunny days in the country every year. For this reason, the use of solar energy can increase the energy pressure of UK, while providing many positive economic benefits. Hence, a Concentrated Solar Power will be a beneficial project to be implemented. In addition, it will help UK dispose of its reliance on oil and make an incredible commitment to the nearby economy, while likewise securing the neighborhood climate. Simultaneously, they additionally approximately $75.2 \mathrm{million}$ of state-ensured venture, so they can better handle assets. As per the MS Project, the whole venture will begin in January 2022 and end of 2023, and the assessed cost of the whole undertaking will reach to 385.5 million with Hot Salt Storage [1]. There are two achievement days, to be specific "Completing Mirrors Parts" and "Beginning foster the Hot Salt Storage". Both are significant defining moments in the venture.

The organization's top managerial staff and designers are required to collaborate during the interaction. Also is to work out the Net Present Value (NPV), internal Rate of Return(IRR) and other expense spending issues of the whole venture for the development of Hot Salt Storage. In any case, the outcome is that the development of Hot Salt Storage will significantly build the ensuing pay to reimburse the advance straightaway, and afterward begin to procure the profit one year early [2]. This research uses qualitative and qualitative methods to analyze the importance of construction management at solar power station in the UK. Some of the methods used for the purpose of this research include, interviews, questionnaire, and academic research on report done by scholars on construction management.

The purpose of the study is to analyze the importance of construction management at solar power station in the UK.The research aims to achieve the following objectives;to analyze the role construction management plays in solar power project.To explore the meaning of cost control in construction management and its effect on the entire project.To explore the importance of construction management in solar power project.

\section{ESTIMATED PRICE OF BID PROJECTS IN THE DIRECTION OF PROJECT MANAGEMENT}

In 2022 , it is estimated that approximately $€ 378.5$ million consumption will be contributed progressively, 
and the entire project will be finished and acknowledged in end of 2023. Furthermore, cost will increment by $€ 20 / \mathrm{MWh}$ by having Hot Salt Storage technology [2].

There are two endowments' choices given by the public authority. The first is a capital appropriation of $€ 50$ million in year 1 , and pay a cost of $€ 130 / \mathrm{MWh}$. As indicated by Cost Engineer, the annual power generation is assessed to be $438,000 \mathrm{MWh}$, and the pay between

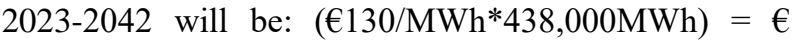
$56,940,000$ [3]. The second is a greater cost of $€ 140 / \mathrm{MWh}$ without the sponsorships. Whenever determined at $€ 140$, the pay between 2023-2042 will be around $438,000 \mathrm{MWh} * € 140=€ 61,320,000$. Hence, they all benefit for those choices is about $€ 662$ million and $€ 695$ million [3]. The distinction between those two choices is about $€ 40$ million which shows that without government's endowment will be more beneficial for the undertaking and having more financial plan space.

With the assumption that the solar power station will be utilized by the end of 2023, the adjustment of NPV/IRR will be found in the above figure. Assuming financial backers need to arrive at the IRR 9\% objective as fast as could be expected; having government's endowment will be a decent decision, since it will have reached $9 \%$ in 2031. Thought about without the appropriation, it will not reach $9.43 \%$ until 2035 [4]. In any case, these two techniques enjoy their own benefits. In the event that financial backer glance at long haul returns, the subsequent choice is worth to choose, on the grounds that the 20-year all out valuation return has reached about $€ 695$ million, however this option bears high risk the beginning phase, on the grounds that there is no administration backing of 50 million in Year1, so assuming financial backer need to make specialized enhancements, it is as yet hard for the group, and the expense of building a Hot Salt Storage is $€ 32$ million in the beginning phase, like the present circumstance might be halted because of inadequate spending plan [5]. Regardless of whether Option 1 will come to the $8 \%$ IRR target prior (Figure1, Figure 2), yet the accompanying power cost is just $110 / \mathrm{MWh}$, which is not so objective contrasted with choice 2 (Figure 3, Figure 4).

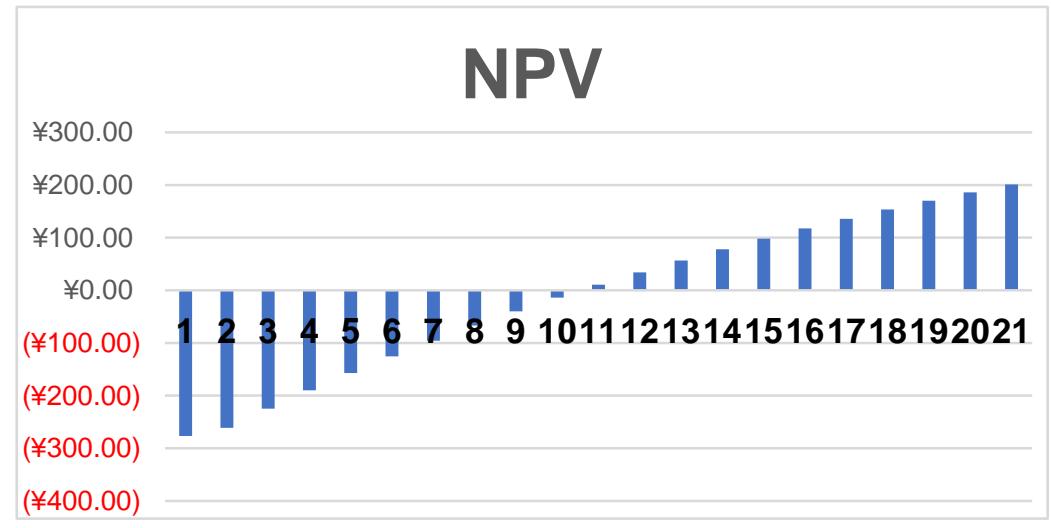

Figure 1 the NPV of the option 1

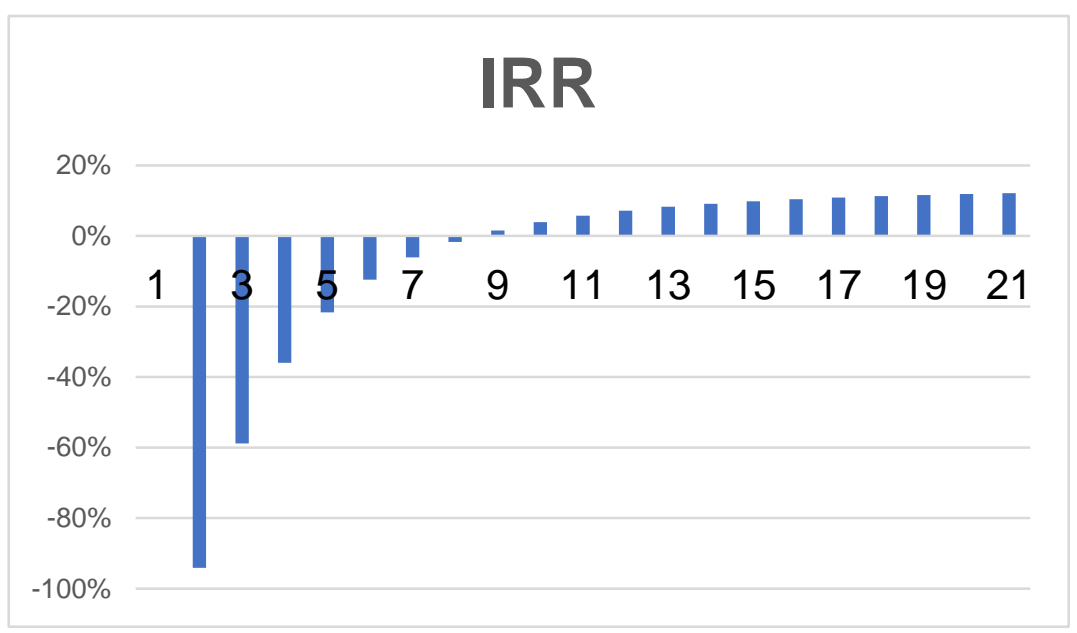

Figure 2 the IRR of the option 1 


\section{NPV}

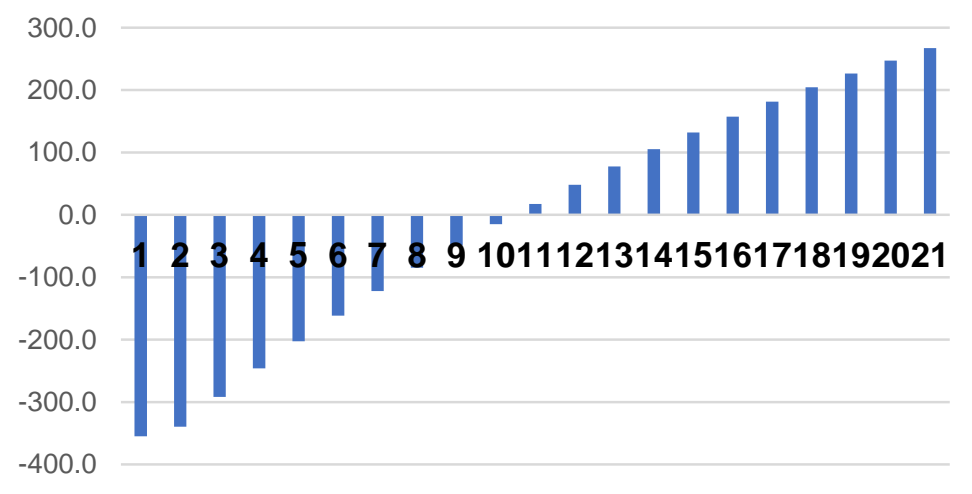

Figure 3 the NPV of the option 2

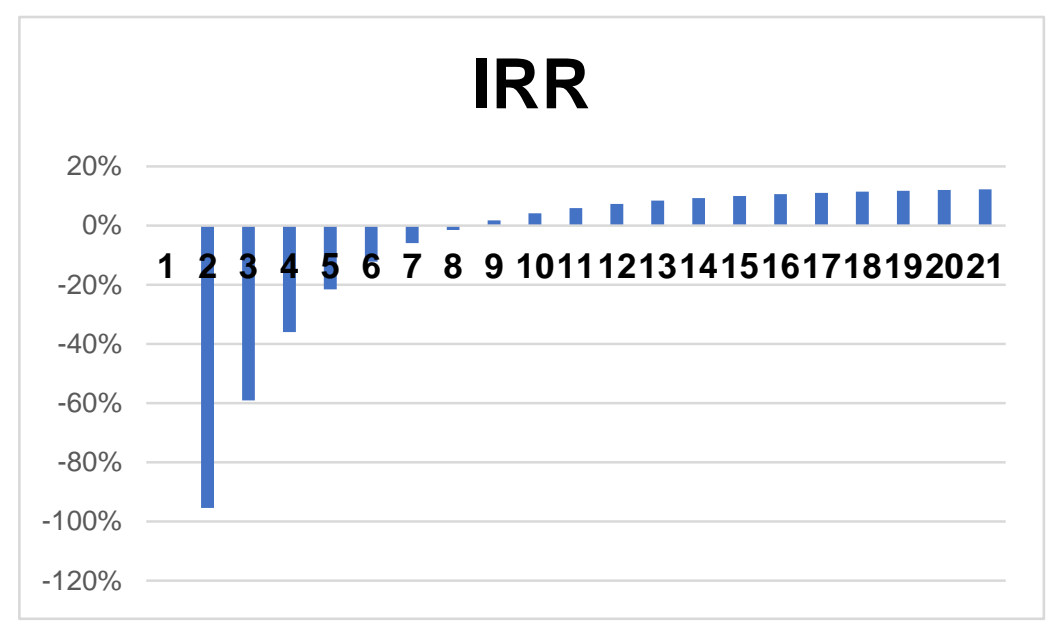

Figure 4 the IRR of the options 2 [2]

It is important to highlight that during the development, there is another issue that should be considered is the issue of energy stockpiling. Thermal Engineer proposed to utilize hot salt to store sun based energy on the grounds that the warm salt energy storage technology will extraordinarily further develop the work effectiveness of the whole task, yet this innovation has numerous hardships and vulnerabilities, including high introductory venture, specialized investigating and specialized faculty booking [5]. It might dial back the advancement of the venture. As indicated by the Thermal Engineer if salt storage option is incorporate, this will likewise must be tried before the entire framework test can start (2023).

Therefore, the whole framework should be tried after the whole framework is built, and the absence of applicable experience is the greatest danger of this task. In the event that the Thermal Engineer neglects to provide a strong answer for a period, all things considered, the public authority and unfamiliar speculation will lose certainty and suspend the following round of venture, which will be a major hit to the whole undertaking around then [6]. In any case, it will be proposed arrangements from a sensible point in the close to give that hot salt stockpiling are as yet satisfactory.

It is important too note that the project will lessen the portion of UK's sustainable power sources from 15.9\% expanded to $25.9 \%$. This shows that this influence impact is extremely fruitful. In the event that the point of view is stretched out to a more extended distance, the CSP task will not just acquire benefits power, however disposing of the reliance on oil what is undeniably significant. Like Sweden, they have figured many duty approaches to urge individuals to travel earth and diminish production line discharges [6]. The justification for this is to support the improvement of new energy sources, so the source of financial control can be recuperated.

\section{CONSTRUCTION MANAGEMENT}

Part of personnel management is creating training of employees and offering the assets they need to keep awake currently in their positions (Figure 5). A portion of those resources includes an on position library of production data, 
empowering workers to advance with their schooling by financing educational cost costs and advising representatives of courses and classes that would aid the advancement of their work capability. When exploited thusly, staff the board keeps the labor force current on the progressions in the business. It permits the organization to adjust speedier to alteration and maintain one in front of the opposition [7]. Human resource experts center the board's staff from the employee's initial meeting through the remainder of the worker's residency. Serious compensation plan and advantages bundles tempt employees to work for the organization. Continuous organization of advantages, worker professional success, and an intuitive survey process by the departmental manager assist the employees in creating their greatest potential. When faculty the executives are compelling for every worker from the start of business, it brings about a higher standard for dependability.

Effective personnel management makes solid connections between the association and the worker. Likewise, it urges employees to foster an emotion of group effort, as indicated by the Free MBA site. One of the more significant connections for any organization is the one between a chief and an employee. By fostering the employee and the organization, the staff sees what its activities mean for the efficiency of the whole division, as per the Management Study Guide site [7]. When employees take an individual interest in the usefulness of their specialization, this assists administrators with zeroing in additional on departmental techniques and worker improvement while zeroing in less on regulatory responsibility, for example, debate goal and worker revenue. successful labor force. A personnel management branch of any association is answerable for human resource and human resources related issues, for example, the identifiable evidence of the labor needs in the organization, the enlistment of the fundamental workers to fill the distinguished labor prerequisites, and actions pointed toward squeezing the chose work into places that match their capability [4]. The significance of faculty the executives can equally be found in its actions toward improving human resources.

Regarding labor planning, the significance of staff the executives includes assessing the present and prospect labor prerequisites of the association. Data on the exacting labor wants will assist the staff division in knowing the specific quantity of representatives expected to fill open opportunities and to make projections concerning the imaginable prospect labor prerequisite of the organization. This information is likewise essential for arranging the various sorts of direction and preparing for various workers. A functional board classic design is utilized to decide the progressive system and authority of individuals associated with a particular task. The design characterizes each colleague's capacity and the detailing lines in a graph for colleagues to reference during a task. For example, a functional construction management organizational structure sorts out its chain of command around generally working offices [7]. A utilitarian chief head every division and reports to a leader. These utilitarian chiefs, not other staff, arrange the venture, and they select colleagues from every office to help the task, notwithstanding their useful obligations.

It is important to note that personnel management is recognized with its pertinence in the association of a

\section{Executive Officer}

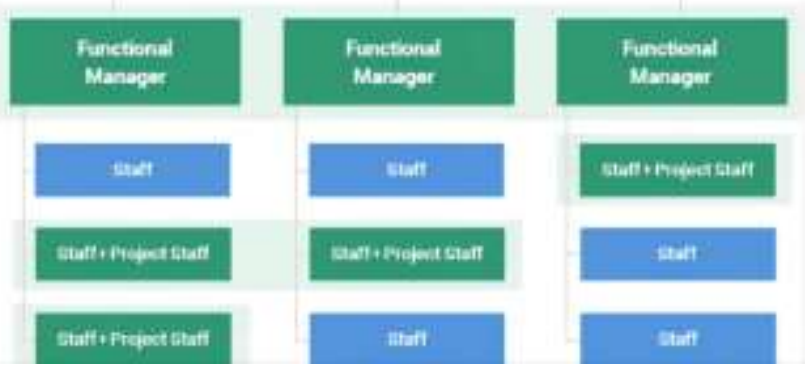

Figure 5 Functional organization structure of construction management. Source: [5]

\section{THE IMPORTANCE OF CONSTRUCTION MANAGEMENT}

The construction management industry is a significant area that offers more economic development in the country. The commitment of the development industry to the monetary turn of events and financial exercises contributes a high critical effect on the advancement of the country. The construction industry is likewise supposed to be a speculation-driven area where the government shows exorbitant interest. Government contracts with the development industry to improve a foundation identified with health, transport just as an instruction area. In addition, the construction industry has held consistent amid a torrent of monetary expectations [8]. Short-and long-term projects are yet being executed as development firms continue building and supporting, as allowed by the central government, 
stringently holding fast to the rules to utilize 'fundamental framework laborers.'

It is important to highlight that the construction industry is a vital area of the economy. It includes a variety of exercises like developing, adjusting, keeping up with, fixing, and wrecking structures, and it additionally covers common, mechanical, and electrical designing undertakings.

Construction projects carry with them a solid measure of monetary 'gradually expanding influences.' When chipping away at huge development projects, keeping nearby organizations and labor forces locked in is beneficial. This can be worked with by offsetting the enormous tasks with more modest ventures. A development venture can directly affect neighborhood organizations by employing nearby specialists to join the work group and acquiring unrefined substances from neighborhood sources [8]. This turns out more revenue for the utilized organizations to give to others around the space.

Long-term laborers at a building site frequently need different conveniences like food, transitory lodging, and clothing administrations. The nearby organizations in space can consider these requirements, from neighborhood cafes to lounges, cabins, and service stations. Therefore, development ventures would contribute in a roundabout way to financial recovery locally. As per history, construction is an area that contributes enormously to economic development. After the Second World War, construction helped the recovery of the U.S. economy by giving reasonable lodging to families and people who passed on the urban areas to get comfortable in new rural areas. Before long, the new networks pulled in organizations that needed to have business structures raised malls, carports, vehicle parks, and films, among others [8]. The opening up of new regions likewise brought a need for street development and fixes, causing a blast in the business and economy all in all.

In real life, construction activities in the United States have contributed to the growth of the economy. Also, in the project, construction management plays the a vital role to ensure that the construction is done on schedule and in the required specification-for instance, the construction of Hudson Yard in New York. The project involves developing real estate development in the Hudson yard and Chelsea neighboring Manhattan in New York. Upon the completion, 13 of the 16 planned structures on the west side of midtown would sit on a platform built over the west side Yard. The project will have an impact on the economy in various ways. To start with, the project will create employment. Being a mega project, it will create employment from engineers, project managers, machinery operators, and casual laborers. It is important to highlight that unemployment is one of the things that affect the economy negatively
[9]. Therefore, by creating employment for hundreds of people, the project will have helped the country's economy. Data on the exacting labor wants will assist the staff division in knowing the specific quantity of representatives expected to fill open opportunities and to make projections concerning the imaginable prospect labor prerequisite of the organization. A serious compensation plan and advantages bundle tempts representatives to work for the organization. A development venture can directly affect neighborhood organizations by employing nearby specialists to join the workgroup and acquiring unrefined substances from neighborhood sources.

In addition, upon completion, the real estate will attract domestic and foreign investors in the estate, which will contribute to the expansion of business and help develop a good relationship with the foreign investors. In this case, it is worth noting the construction managers play great roles in managing the construction and acting as a link between the Client and the workforce. Construction managers facilitate communication between players engaged in a development project. This guarantees that the proprietor's vision for the undertaking is recognized and clung to throughout the project [10]. The workforce is inclusive of engineers, architects, laborers, and surveyors. Maintaining a good relationship between the two makes the construction go on smoothly and ensures that the objectives of the projects are being met. It is, therefore, important to acknowledge that construction managers are the core to the success of the project. The project's impact on the economy indicates how the construction industry is essential in any country.

\section{CONCLUSION}

In conclusion, construction management guarantees that every partner in the project is considered responsible for their necessary portion. This is critical to guarantee that you are paying for is the thing that you are getting. Precise assessment of the development cost of a task is critical development cost assessment, when in doubt, proceeds in one of two ways. The Client gives the fashioner the most outrageous monetary arrangement figure, the limit for development cost, or a major season of study where potential plans are made and their different costs evaluated. Human resource experts center the board's staff from the representative's initial meeting through the remainder of the worker's residency by the laws of the organic market. Overemphasized and under-focused on developing markets will influence the level and nature of rivalry just as the costs charged. Further research should be done on how effective personnel management makes solid connections between the association and the worker. One of the more significant connections for any organization is the one between a chief and an employee. 
By fostering the employee and the organization, the staff sees what its activities mean for the efficiency of the whole division, as per the Management Study Guide site. The article has proved that construction management is essential in the development of solar power station in the UK.

\section{REFERENCES}

[1] Al-Ghezi, M. K. Heat accumulation system for solar power station with parabolic trough solar collector. Elixir Int J Elixir Renew Energy, 2018,119, 51122-51125.

[2] Araujo, A. G., Carneiro, A. M. P., \& Palha, R. P. Sustainable construction management: A systematic review of the literature with meta-analysis. Journal of Cleaner Production, 2020, 256, 120350.

[3] Ballard, G., \& Howell, G. A. Competing construction management paradigms. In Construction Research Congress: Wind of Change: Integration and Innovation, 2003, pp. 1-8.

[4] Cao, Y., Zandi, Y., Agdas, A. S., Wang, Q., Qian, X., Fu, L., \& Roco-Videla, A. A review study of application of artificial intelligence in construction management and composite beams. Steel and Composite Structures, 2021, 39(6), 685-700.

[5] Cárdenas, B., Swinfen-Styles, L., Rouse, J., Hoskin, A., Xu, W., \& Garvey, S. D. Energy storage capacity vs. renewable penetration: A study for the UK. Renewable Energy, 2021, 171, 849-867.

[6] Chen, L., \& Pan, W. Review fuzzy multi-criteria decision-making in construction management using a network approach. Applied Soft Computing, 2021, 107103.

[7] Fan, G., Duan, B., Zhang, Y., Li, X., \& Ji, X. Full-spectrum selective thin film based photonic cooler for solar cells of space solar power station. Acta Astronautica, 2021, 180, 196-204.

[8] Halpin, D. W., Lucko, G., \& Senior, B. A. Construction management. John Wiley \& Sons. 2017.

[9] Harris, F., McCaffer, R., Baldwin, A., \& Edum-Fotwe, F. Modern construction management. John Wiley \& Sons. 2021.

[10] Huang, C., Hou, H., Hu, E., Liang, M., \& Yang, Y. Impact of power station capacities and sizes of solar field on the performance of solar aided power generation. Energy, 2017, 139, 667-679. 